\title{
Development and Validation of Micro Emulsion High Performance Liquid Chromatography(MELC) Method for the Determination of Nifedipine in Pharmaceutical Preparation
}

\author{
AL-Jammal MKH, Al Ayoub Y and Assi KH* \\ Bradford School of Pharmacy, School of Life Sciences, University of Bradford BD7 1DP, UK
}

\begin{abstract}
Microemulsion is a stable, isotropic clear solution consisting of oil based substance, water surfactant and cosurfactant. There are two types of microemulsion which are used as a mobile phase; water in oil (w/o) and oil in water (o/w).Microemulsion has a strong ability to solubilize both hydrophobic and hydrophilic analytes, therefore reducing the pre-treatment of the sample which is needed for the complex sample. Recent reports found that separating the analytes by using microemulsion high performance liquid chromatography can be achieved with superior speed and efficiency compared to conventional HPLC modes. In this work, Oil in water (o/w) microemulsion has been used for the determination of nifedipine in pharmaceutical preparation. The effect of each parameter on the separation process was examined. The samples were injected into $\mathrm{C} 18$, analytical columns maintained at $30^{\circ} \mathrm{C}$ with a flow rate 1 $\mathrm{ml} / \mathrm{min}$. The mobile phase was $87.1 \%$ aqueous orthophosphate buffer $15 \mathrm{mM}$ (adjusted to $\mathrm{pH} 3$ with orthophosphoric acid), $0.8 \%$ of octane as oil, 4.5 SDS, and $7.6 \% 1$-butanol, all w/w. The nifedipine and internal standard peaks were detected by UV detection at $\lambda$ max $237 \mathrm{~nm}$

The calibration curve was linear $\left(r^{2}=0.9995\right)$ over nifedipine concentrations ranging from 1 to $60 \mu \mathrm{g} / \mathrm{ml}(\mathrm{n}=6)$. The method has good sensitivity with limit of detection (LOD) of $0.33 \mu \mathrm{g} / \mathrm{ml}$ and limit of quantitation (LOQ) of $1.005 \mu \mathrm{g} /$ $\mathrm{ml}$. Also it has an excellent accuracy ranging from 99.11 to $101.64 \%$. The intra-day and inter-day precisions (RSD $\%$ ) were $<0.45 \%$ and $<0.9 \%$, respectively.
\end{abstract}

Keywords: High-Performance Liquid Chromatography; Microemulsion; Determination; Validation; Nifedipine

\section{Introduction}

Microemulsion is thermodynamically stable liquid solution composed of water, oil, surfactant and medium chains of alcohol [13]. Microemulsions have many distinctive features including high solubilisation capacities for both polar and non-polar compounds, low interfacial tensions, fine microstructures, and spontaneous formation [2,4-26].

Different types of microemulsions can be formed, however only two of these, water in oil (w/o) and oil in water $(\mathrm{o} / \mathrm{w})$, have been used as mobile phases for separation by high performance liquid chromatography (HPLC). Previous studies have shown that W/O microemulsions are suitable as mobile phases for normal-phase chromatography, while $\mathrm{O} / \mathrm{W}$ microemulsions are useful eluents for the reversed phase HPLC. Recent reports have found that separations can be achieved with superior speeds and efficiencies using microemulsion, when compared to conventional HPLC modes. Microemulsions also offer unique selectivity with excellent resolution and the capability for quantitative and stability-indicating analyses $[4,27,28]$. Recently, O/W microemulsion has been widely used for the separation of mixtures of test solutes and pharmaceutical compounds [10-13]. Many of the previous studies employed non-ionic surfactants for the preparation of microemulsion mobile phases; however, it was reported that this type of mobile phase lacks the ability to separate highly hydrophilic compounds that have very similar chemical properties [15].

The reported methods for the analyses of nifedipine used conventional mobile phases that were based on the use of a large volume of organic solvent. The main drawback of the conventional mobile phase is that the organic solvent waste increases the burden on the environment, as well as being costly to dispose of [4,7]. However, the microemulsion mobile phase has an excellent solubilisation capability for both hydrophobic and hydrophilic analytes [8-10], and would be suitable for the determination of nifedipine in pharmaceutical preparations.

In this work, it has been proposed to extendour previously published method [17] to quantify nifedipine in pharmaceutical preparations. The effects of the operating parameters on the separation performance will be studied and the method will be validated for the determination of nifedipine in pharmaceutical preparations.

\section{Experimental}

\section{Materials and chemicals}

Nifedipine $\geq 98 \%$ powder and Felodipine solid were purchased from Sigma-Aldrich, china. Sodium n-dodecyl sulfate $99 \%$ and 1-butanol (HPLC grade 99\%) and potassium dihydrogen phosphate were purchased from Alfa Aesar, Heysham, England. Acetonitrile, HPLC grade was purchased from Fisher chemical, United Kingdom. nifedipine $10 \mathrm{mg}$ capsules and nifedipine (nifedipress ${ }^{\circ}$ ) MR $20 \mathrm{mg}$ tablet were purchased from TEVA UK Limited, Esatbourn.

*Corresponding author: Assi KH, Bradford School of Pharmacy, School of Life Sciences, University of Bradford BD7 1DP, UK, Tel: 00441274234703; E-mail: k.h.a.assi@bradford.ac.uk

Received December 08, 2015; Accepted February 24, 2015; Published March 03, 2015

Citation: AL-Jammal MKH, Al Ayoub Y, Assi KH (2015) Development and Validation of Micro Emulsion High Performance Liquid Chromatography(MELC) Method for the Determination of Nifedipine in Pharmaceutical Preparation. Pharm Anal Acta 6: 347. doi:10.4172/2153-2435.1000347

Copyright: () 2015 AL-Jammal MKH, et al. This is an open-access article distributed under the terms of the Creative Commons Attribution License, which permits unrestricted use, distribution, and reproduction in any medium, provided the original author and source are credited. 


\section{Chromatographic conditions}

The HPLC System was waters 2695 Separations Module which provides quaternary solvent. Chromatographic separation was performed using a $250 \mathrm{X} 4.60 \mathrm{~mm}, 5 \mu \mathrm{m}$ particle size (spherisorb C18) column. The mobile phase was prepared by weighting $4.5 \%$ of SDS as surfactant, $7.6 \%$ of butanol as co-surfactant , $0.8 \%$ of octane as oil, which then dissolved in $87.1 \%$ of $15 \mathrm{mM}$ phosphate buffer (adjusted to $\mathrm{pH} 3$ with Ortho phosphoric acid), all w/w (weight ratio of each component to the total weight). The solution was then sonicated for $10 \mathrm{~min}$. The mobile phase was filtered under vacuum through a 0.45 $\mu \mathrm{m}$ filter and degassed in an ultrasonic bath under vacuum for $10 \mathrm{~min}$. The nifedipine samples and felodipine (as an internal standard) were injected into the system and separated at $30^{\circ} \mathrm{C}$ and at $\lambda$ max $237 \mathrm{~nm}$. The mobile phase was delivered at a flow rate $1.0 \mathrm{ml} / \mathrm{min}$ and injection volume was $20 \mu \mathrm{l}$.

The column was conditioned before each experiment using a mixture of acetonitrile: water $(50: 50 \% \mathrm{v} / \mathrm{v})$ for $30 \mathrm{~min}$ at flow rate of $1 \mathrm{ml} / \mathrm{min}$. The microemulsion mobile phase was then flushed through the HPLC system for $30 \mathrm{~min}$ before the first injection. Column cleaning was performed by flushing the column a mixture of acetonitrile and water $(50: 50, \mathrm{v} / \mathrm{v})$ for 2 hour and followed by acetonitrile $100 \%$ for 1 hour.

\section{Particle size measurement of the mobile phase}

The particle size of the mobile phase was measured using Zetasizer, the measurement was carried out at $25^{\circ} \mathrm{C}$, by using special cuvette (low volume disposable sizing cuvette) at count rate (kcps) of 153.2. The majority of particles are less than $10 \mathrm{~nm}$.

\section{Preparation of nifedipine solution and internal standard solution (felodipine)}

A suitable amount of nifedipine (100 mg) was weighed into $1000 \mathrm{ml}$ of volumetric flask which was covered by foil to protect the solution from the light, because nifedipine is sensitive to the light (31). The solute was dissolved using methanol HPLC grade. A stock solution of nifedipine was prepared at concentration of $(100 \mu \mathrm{g} / \mathrm{ml})$ using the internal standard solution. The internal standardsolution was prepared beforehand at concentration of $(100 \mu \mathrm{g} / \mathrm{ml})$ in the mobile phase.

Calibration standards in the concentration range of $2.5,5,10,20$, 40 , and $60 \mu \mathrm{g} / \mathrm{mL}$ were prepared in the appropriate volumetric flasks using internal standard solution. All standards/samples were filtered through a $0.45 \mu \mathrm{m}$ filter prior injection

\section{Result and Discussion}

\section{Optimization of mobile phase}

Concentration of surfactant: The effect of surfactant concentration on the retention time of nifedipine was examined over a range of 2.5$4.5 \% \mathrm{w} / \mathrm{w}$. This range was selected because there was no microemulsion formed below $2.5 \% \mathrm{w} / \mathrm{w}$. On the other hand, high backpressure was generated at concentration above $4.5 \%$. It was found that the retention time decreases as the concentration of surfactant increases. This relates to the fact that the surfactant molecules adsorb on the surface pores of the stationary phase and reduces the surface area of the stationary phase and hence changes the efficiency of the column $[5,11,12]$. Also an increase in the surfactant concentration leads to an increase in the volume of microemulsion droplets flowing towards the detector which in turn decreases the solute retention time $[12,13]$. This effect is more significant for lipophilic solutes which have a high affinity to oil droplets. (Figure 1) represents the effect of surfactant concentration on retention time.

Concentration of the Co-surfactant: (Figure 2) shows the effect of changing the concentration of co-surfactant on the retention time of nifedipine. The findings of this study show that the retention time of nifedipine decreases with increasing the concentration of co-surfactant between $5.6-8.6 \% \mathrm{w} / \mathrm{w}$. The decrease in the retention time of nifedipine is due to the fact that the solubilisation capacity of microemulsion increases with the use of co-surfactant which in turn improves the solubility of nifedipine in the microemulsion mobile phase [14]. On the other hand, a further increase of butanol concentration has no marked effect on the retention time and also concentration below $5.6 \mathrm{w} / \mathrm{w} \%$ produced an unstable microemulsion system indicating that the cosurfactant has a very important role in the stability of microemulsion.

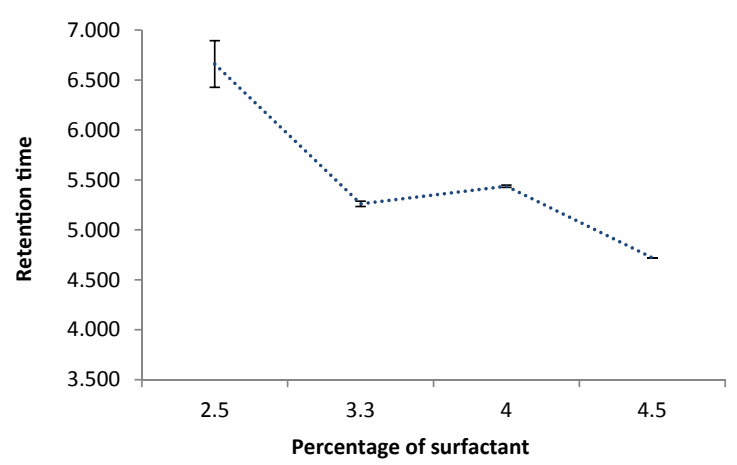

Figure 1: Effect of surfactant concentration on retention time.

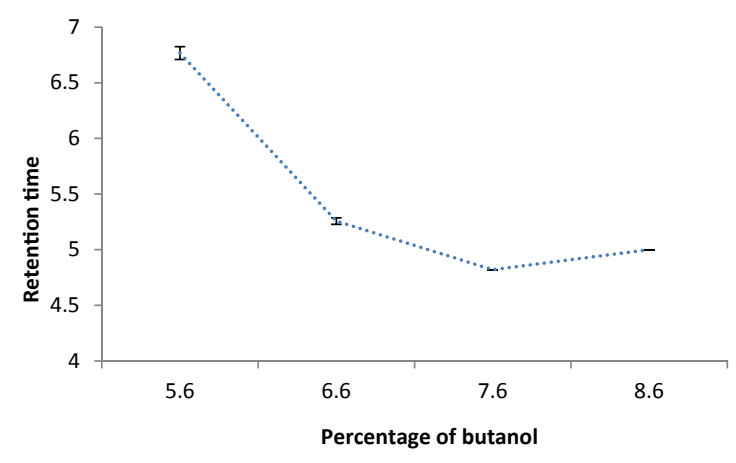

Figure 2: Effect of co-surfactant concentration on retention time.

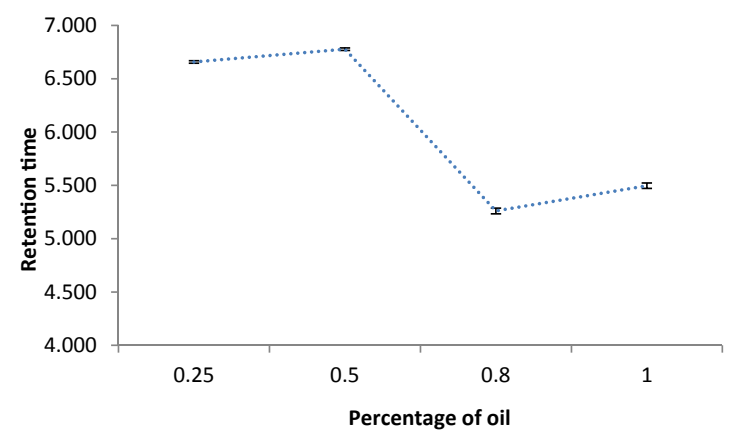

Figure 3: Effect of oil concentration on retention time. 
Concentrations greater than $8.6 \%$ wouldn't be viable due to the increased column back pressure $[15,16]$.

Concentration of the oil: Different concentrations of oil (ethyl acetate) were investigated in the range $0.25-1.0 \% \mathrm{w} / \mathrm{w}$. (Figure 3 ) shows that the retention time of nifedipine decreases with increasing theconcentration of oil, nifedipine islipophilic solute and hasgreater affinity tothe oil droplet rather than to the water phase $t[17,18]$.

Effect of concentration of phosphate buffer: The effect of buffer concentration on the retention time of nifedipine was studied over the concentration ranges of $2.5-20 \mathrm{mM}$. It was found that retention time decreases with increasing buffer concentration. These results are in agreement with the findings reported by Mao et al. [23]. However, Mao et al. have studied the effect of buffer concentration using conventional mobile phase [20]. The consistency in both studies shows that in reverse phase chromatography, the retention time of positively charged analytes decreases with increasing the buffer concentration whether the mobile phase contains microemulsion or not. This indicatesthat there was an interaction between protonated analytes (nifedipine) and the silanol group [17]. (Figure 4) also shows that the effect of buffer concentration is minimal above $10 \mathrm{mM}$ and therefore $10 \mathrm{mM}$ was chosen for optimum separation.

Effect of column temperature: In conventional reversed phase separation, the temperature has direct effect on the retention time and hence the separation of basic drugs. It was reported that as temperature increases the neutral form of basic drugs increases and the protonated form decreases due to change in dissociation constant of basic drug $[21,22]$. The neutral form interacts more strongly with the surface of porous stationary phase, which is considered an important factor for controlling the separation in reverse phase chromatography $[20,23,24]$. On the other hand, the temperature has very little effect on the separation in a HPLC microemulsion system.In this system, there are two different and simultaneous mechanisms, one of the mechanisms states that the basic drugs become more neutral and hence they are retained longer in the stationary phase. While the other mechanism indicates that the neutral form has more tendencies to deposit in the oil droplets and therefore the retention time decreases. (Figure 5) shows that there is no marked effect on retention time when increasing the temperature $[17,25]$. Nevertheless, better peak efficiency was obtained at high temperature (Figure 6)

Optimum mobile phase: Considering the effect of surfactant, co-surfactant, oil, phosphate buffer and temperature parameters on microemulsion separation, and based on the above results, the optimum microemulsion mobile phase for separation of nifedipine and felodipine is shown in (Table 1) using $\lambda \max 237 \mathrm{~nm}$, flow rate 1 $\mathrm{ml} / \mathrm{min}$ and injection volume $20 \mu \mathrm{l}$ (Figure 7) shows a representative chromatogram using the optimum condition.

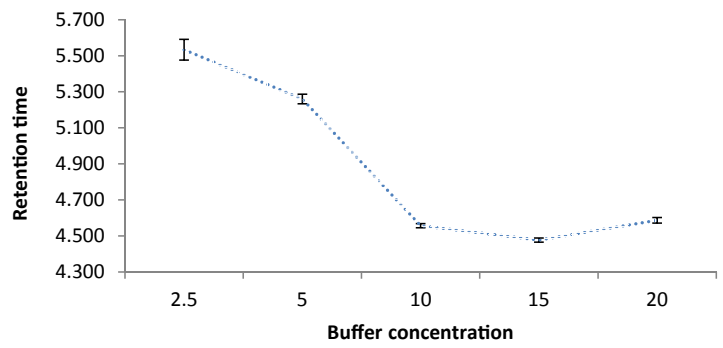

Figure 4: Effect of phosphate buffer concentration on retention time.

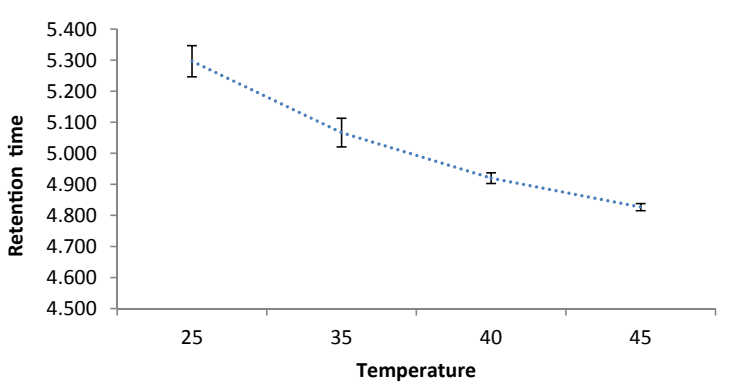

Figure 5: Effect of column temperature on retention time.
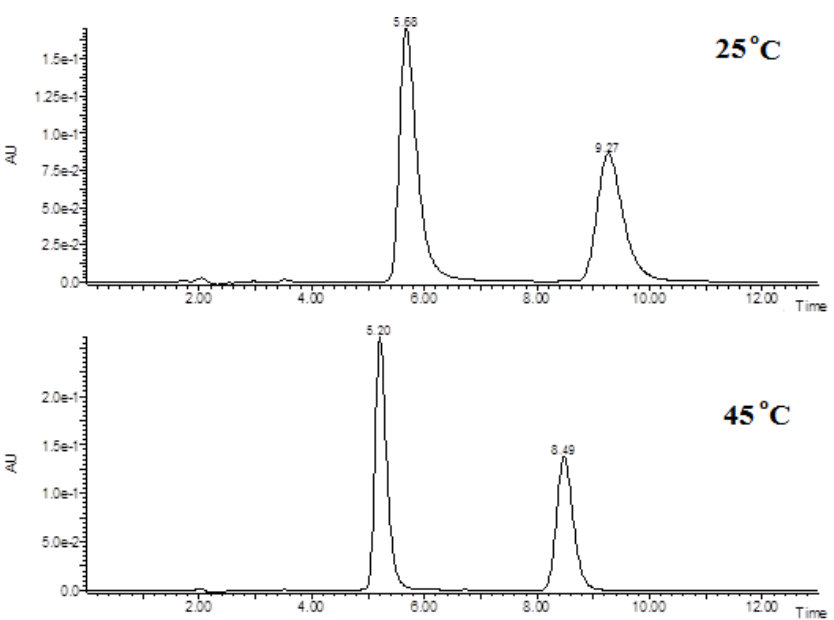

Figure 6: Shows the difference in efficiency and resolution at differen temperature $25^{\circ} \mathrm{C}$ and at $45^{\circ} \mathrm{C}$

\section{Method validation}

The method was validated in accordance with the ICH guidelines [29].

Linearity: Seven concentrations of nifedipine $(1,2.5,5,10,20$, $40,60 \mu \mathrm{g} / \mathrm{ml}$ ) were prepared including the limit of quantification. The calibrations standards were injected in duplicates together with the blank samples. The detector response was shown to be linear over the range of 1 to $60 \mu \mathrm{m} / \mathrm{ml}$ and gave a regression coefficient $\left(\mathrm{R}^{2}\right)$ of 0.9998 and $\mathrm{Y}=0.0624 \mathrm{x}-0.0185$

Sensitivity: The sensitivity was expressed as limit of detection (LOD) and limit of quantitation (LOQ). The LOQ and LOD were determined using the following equations:

$$
L O D=\frac{3.3 \sigma}{S} \quad L O Q=\frac{10 \sigma}{S}
$$

Where $(\sigma)$ the standard deviation of $y$-intercept and $S$ is the mean slope of the calibration curves $(n=5)$. The limit of detection (LOD) was $0.332 \mu \mathrm{g} / \mathrm{ml}$ and limit of quantitation (LOQ) was $1.005 \mu \mathrm{g} / \mathrm{ml}$

Selectivity: This method showed good selectivity for nifedipine and internal standard (felodipine) (Figure 7). Although chemical structure for felodipine and nifedipine is very similar, good separation was achieved. Therefore this method has high selectivity for both nifedipine and felodipine. Vidadhara et al. [30] reported the determination of nifedipine in pharmaceutical dosage forms using conventional mobile phase with reversed phase C18 column (Platinum EPS, 5 um, 250x4.6 


\begin{tabular}{|c|c|c|c|c|c|c|}
\hline $\begin{array}{c}\text { Surfactant (SDS) } \\
\mathbf{w} / \mathbf{w} \%\end{array}$ & $\begin{array}{c}\text { Co-surfactant } \\
\text { (butanol) w/w\% }\end{array}$ & Oil (octane) w/w \% & \multicolumn{2}{|c|}{ Phosphate buffer w/w\% } & $\begin{array}{c}\text { Column } \\
\text { temperature }\left({ }^{\circ} \mathbf{C}\right)\end{array}$ & $\begin{array}{c}\text { Retention Time } \\
\text { (buncentration }\end{array}$ \\
\hline 4.5 & 7.6 & 0.8 & 87.1 & $15 \mathrm{mM}$ & 30 \\
\hline
\end{tabular}

Table 1: Shows the optimum parameter of mobile phase.

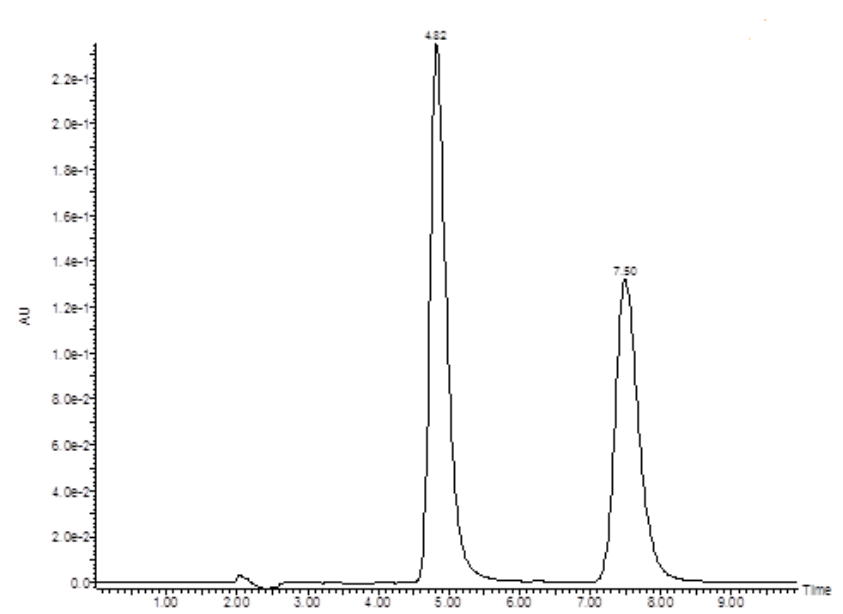

Figure 7: Representative chromatograph using the optimum microemulsion mobile phase for separation of nifedipine and felodipine. Peak identities: nifedipine $4.82 \mathrm{~min}$, and felodipine $7.5 \mathrm{~min}$.

\begin{tabular}{|c|c|c|}
\hline $\begin{array}{c}\text { Actual concentration } \\
(\boldsymbol{\mu} \mathbf{g} / \mathbf{m l})\end{array}$ & $\begin{array}{c}\text { Observed concentration } \\
(\boldsymbol{\mu g} / \mathbf{m l})\end{array}$ & \% Accuracy \\
\hline 4 & 4.01 & 100.23 \\
\hline 15 & 15.246 & 101.64 \\
\hline 50 & 49.56 & 99.11 \\
\hline
\end{tabular}

Table 2: Shows the range of accuracy for Nifedipine.

\begin{tabular}{|c|c|c|}
\hline \multirow{2}{*}{ Nominal concentration $(\boldsymbol{\mu m} / \mathbf{m l})$} & \multicolumn{2}{|c|}{ \% Relative Standard Deviation ( RSD) } \\
\cline { 2 - 3 } & Intra-day & Inter-day \\
\hline low=4 & 0.26 & 0.87 \\
\hline medium=15 & 0.11 & 0.92 \\
\hline high=50 & 0.50 & 0.26 \\
\hline
\end{tabular}

Table 3: Shows the range of \%RSD for both intra-day and inter-day precision.

$\mathrm{mm})$. Although the retention time is similar in both methods, the conventional published method utilized high proportion of organic solvents, $80 \%$ of the total mobile phase, which increases the burden on the environment and the cost of waste disposal $[13,14]$.

Accuracy: Three different solutions of nifedipine were prepared at different concentrations to include three levels low $(4 \mu \mathrm{g} / \mathrm{ml})$, medium $(15 \mu \mathrm{g} / \mathrm{ml})$ and high $(50 \mu \mathrm{g} / \mathrm{ml})$. Each level was repeated six times. The accuracy percentage ranged from 99.11 to $101.64 \%$ (Table 2).

Precision: Precision was studied using five determinations at known concentration levels corresponding to low $(4 \mu \mathrm{m} / \mathrm{ml})$, medium $(15 \mu \mathrm{m} / \mathrm{ml})$ and high $(50 \mu \mathrm{m} / \mathrm{ml})$ levels in the calibration range. The same study was repeated for 5 days to determine the inter-day variation. The precision expressed by the percentage relative standard deviation (\%RSD).The \%RSD for intra-day precision ranged from $0.25-0.49 \%$ whereas the $\%$ RSD for the inter-day was $0.26-0.91 \%$ (Table 3 ).

Recovery: The recovery of nifedipine from both capsule and tablet dosage form were assessed by extracting nifedipine from the dosage form according the British pharmacopeia 2012. The recovery was assessed at three different levels low $(5 \mu \mathrm{g} / \mathrm{ml})$ and medium $(20 \mu \mathrm{g} /$

\begin{tabular}{|c|c|c|}
\hline $\begin{array}{c}\text { Concentration of } \\
\text { nifedipine }(\boldsymbol{\mu g} / \mathbf{m l})\end{array}$ & $\begin{array}{c}\text { measure amount for one } \\
\text { capsule } \mathbf{( m g})\end{array}$ & Recovery $\%$ \\
\hline High (40) & 10.015 & 100.15 \\
\hline Medium(20) & 10.04 & 100.34 \\
\hline Low(5) & 10.07 & 100.74 \\
\hline
\end{tabular}

Table 4: Shows the Recovery of the nifedipine capsule $10 \mathrm{mg}$.

\begin{tabular}{|c|c|c|}
\hline $\begin{array}{c}\text { Concentration of } \\
\text { nifedipine( } \boldsymbol{\mu g} / \mathbf{m l})\end{array}$ & $\begin{array}{c}\text { measured amount one } \\
\text { tablet(mg) }\end{array}$ & Recovery\% \\
\hline High $(\mathbf{4 0})$ & 19.95 & 99.76 \\
\hline Medium(20) & 19.86 & 99.32 \\
\hline Low(5) & 20.082 & 100.41 \\
\hline
\end{tabular}

Table 5: Shows the Recovery of the nifedipine tablet $20 \mathrm{mg} \mathrm{MR}$.

$\mathrm{ml})$ and high $(40 \mu \mathrm{g} / \mathrm{ml})(\mathrm{n}=5$ for each level). The extract solution was diluted to give the required concentration for each level. Table 4 shows the range of recovery of nifedipine capsule which was from 100.15 to $100.74 \%$. The recovery for the nifedipine from $20 \mathrm{MR}$ tablets was ranged from 99.32 to $100.4 \%$ (Table 5). This suggests that this method has excellent recovery for both capsule and tablet, even though the tablet form was the modified-release tablets [26].

Robustness: The robustness of the assay method was examined by introducing small deliberate changes in the HPLC conditions which included wavelength (233 and $237 \mathrm{~nm}$ ), concentration ofco-surfactant, surfactant, and oil in the mobile phase $(7.4-7.8 \% \mathrm{w} / \mathrm{w}, 4.3-4.7 \% \mathrm{w} / \mathrm{w}, 0.6-$ $1 \% \mathrm{w} / \mathrm{w}$ respectively) and temperature $\left(30-35^{\circ} \mathrm{C}\right)$. A resolution greater than 2 between nifedipine and felodipine was maintained throughout these experiments.

Stability: The reference solution was stored in the refrigerator at $2-4^{\circ} \mathrm{C}$ for 4 weeks, and re-analysed in an injection sequence and was tested against freshly prepared standard solution. The concentration after such storage conditions and on comparison with a freshly prepared standard was $97 \%$.

\section{Conclusion}

This study has shown that the $\mathrm{O} / \mathrm{W}$ microemulsion mobile phase using SDS surfactant was successfully applied and validated for the determination of nifedipine in aqueous solutions and in the pharmaceutical formulation. The method was robust over a range of \pm $5 \%$ of the experimental condition and over a wide range of temperature. Moreover, it was rapid, precise and accurate.

\section{References}

1. Sjoblom J, Lindberg R, Friberg SE (1996) Microemulsions — phase equilibria characterization, structures, applications and chemical reactions. Adv in Colloid and Interface Sci 65: 125-287.

2. Danielsson I, Lindman B (1981) The definition of microemulsion. Colloids and Surfaces 3: 391-392.

3. Constantinides PP, Scalart JP (1997) Formulation and physical characterization of water-in-oil microemulsions containing long- versus medium-chain glycerides. Int $\mathrm{J}$ of Pharmaceutics 158: 57-68.

4. El-Sherbiny DT, El-Enany N, Belal FF, Hansen SH (2007) Simultaneous determination of loratadine and desloratadine in pharmaceutical preparations using liquid chromatography with a microemulsion as eluent. J of Pharmaceutical and Biomedical Analysis 43: 1236-1242. 
Citation: AL-Jammal MKH, AlAyoub Y, Assi KH (2015) Development and Validation of Micro Emulsion High Performance Liquid Chromatography(MELC) Method for the Determination of Nifedipine in Pharmaceutical Preparation. Pharm Anal Acta 6: 347. doi:10.4172/2153-2435.1000347

Page 5 of 5

5. Andelija M, Darko I, Mirjana M, Biljana J, Slavko M (2006) Influence of structural and interfacial properties of microemulsion eluent on chromatographic separation of simvastatin and its impurities. J Chromatogr A 1131: 67-73.

6. Formariz TP, Chiavacci LA, Sarmento VHS, Franzini CM, Silva-Junior AA, et al. (2008) Structural changes of biocompatible neutral microemulsions stabilized by mixed surfactant containing soya phosphatidylcholine and their relationship with doxorubicin release. Colloids and Surfaces B: Biointerfaces 63: 287-295.

7. Poole CF (2003) Capillary-Electromigration Separation Techniques, in The Essence of Chromatography. Elsevier Science: Amsterdam: 619-717.

8. Altria KD (1999) Application of microemulsion electrokinetic chromatography to the analysis of a wide range of pharmaceuticals and excipients. J Chromatogr A 844: 371-386.

9. Larpentc C, Bernard E, Richard J, Vaslin S (1997) Synthesis of functionalized nanoparticles via copolymerization in microemulsions and surface reactions. Reactive and Functional Polymers 33: 49-59.

10. Watarai H (1997) Microemulsions in separation sciences. Journal of Chromatography A 780: 93-102.

11. Berthod A, Decarvalho M (1992) Microemulsion as mobile phases in liquid chromatography. Analytical Chemistry 64: 2267-2272.

12. Marsh A, Clark BJ, Altria KD (2005) A review of the background, operating parameters and applications of microemulsion liquid chromatography (MELC). Journal of Separation Science 28: 2023-2032.

13. Georges J, Berthod A (1983) Microenvironment influence on the electrochemical oxidation of $\mathrm{N}$-methylphenothiazine in aqueous surfactant solutions and in a O/W microemulsion. Electrochimica Acta 28: 735-741.

14. Garti N, Avrahami M, Aserin A (2006) Improved solubilization of Celecoxib in U-type nonionic microemulsions and their structural transitions with progressive aqueous dilution. J Colloid Interface Sci 299: 352-365.

15. Jeirani Z, Mohamed Jan B, Si Ali B, Noor IM, See CH, et al. (2013) Formulation, optimization and application of triglyceride microemulsion in enhanced oil recovery. Industrial Crops and Products 43: 6-14.

16. Sripriya R, Muthu Raja K, Santhosh G, Chandrasekaran M, Noel M (2007) The effect of structure of oil phase, surfactant and co-surfactant on the physicochemical and electrochemical properties of bicontinuous microemulsion. J Colloid Interface Sci 314: 712-717.

17. Althanyan MS, Assi KH, Clark BJ, Hanaee J (2011) Microemulsion high performance liquid chromatography (MELC) method for the determination of terbutaline in pharmaceutical preparation. J Pharm Biomed Anal 55: 397-402.

18. Li P, Ghosh A, Wagner RF, Krill S, Joshi YM, et al. (2005) Effect of combined use of nonionic surfactant on formation of oil-in-water microemulsions. Int $\mathrm{J}$ Pharm 288: 27-34

19. Lawrence MJ, Rees GD (2000) Microemulsion-based media as novel drug delivery systems. Adv Drug Deliv Rev 45: 89-121.

20. Mao Y, Carr PW (2001) Separation of selected basic pharmaceuticals by reversed-phase and ion-exchange chromatography using thermally tuned tandem columns. Anal Chem 73: 4478-4485

21. Mc Calley DV (2000) Effect of temperature and flow-rate on analysis of basic compounds in high-performance liquid chromatography using a reversedphase column. J Chromatogr A 902: 311-321.

22. Marin SJ, Jones BA, Felix WD, Clark J (2004) Effect of high-temperature on high-performance liquid chromatography column stability and performance under temperature-programmed conditions. J Chromatogr A 1030: 255-262.

23. Mertzman MD, Foley JP (2005) Temperature effects on chira microemulsion electrokinetic chromatography employing the chiral surfactant dodecoxycarbonylvaline. J Chromatogr A 1073: 181-189.

24. Planeta J, Moravcová D, Roth $M$, Karásek $P$, Kahle V (2010) Silica-based monolithic capillary columns-Effect of preparation temperature on separation efficiency. J Chromatogr A 1217: 5737-5740

25. Yang $Y$ (2006) A model for temperature effect on column efficiency in hightemperature liquid chromatography. Analytica Chimica Acta 558: 7-10.

26. Stationery office on behalf of the medicines and health care products Regulation Agency (2011) Pharmacopoeia B, British Pharmacopoeia: 3

27. Marsh A, Altria KD, Clark BJ (2004) Oil-in-water microemulsion high performance liquid chromatographic analysis of pharmaceuticals Chromatographia 59: 531-542.

28. El-Sherbiny DT, Eid MI, El-Wasseef DR, Al-Ashan RM, Belal F (2005) Analysis of flunarizine in the presence of some of its degradation products using micellar liquid chromatography (MLC) or microemulsion liquid chromatography (MELC)-application to dosage forms. J Sep Sci 28: 197-202.

29. Validation of Analytical Procedures (1996) Methodology Q2B, ICH Steering Committee.

30. Vidadhara S, Sasidhar RIC, Praveen Kumar B, Ramarao NT, Sriharita N (2012) Method Development and Validation for Simultaneous Estimation of Atenolo and Nifedipine in Pharmaceutical Dosage Forms by RP-HPLC, Orient $\mathrm{J}$ Chem 28: 1691-1696.

31. Shamsipur M, Hemmateenejad B, Akhond M, Javidnia K, Miri R (2003) A study of the photo-degradation kinetics of nifedipine by multivariate curve resolution analysis. J Pharm Biomed Anal 31: 1013-1019. 